\title{
Psicodinâmica do trabalho e relações sociais de sexo. Um itinerário interdisciplinar. 1988-2002
}

\author{
Pascale Molinier, profa \\ Laboratoire de Psychologie du Travail et de l'Action \\ Conservatoire National des Arts et Métiers \\ 41, rue Gay-Lussac \\ 75005 Paris França \\ E-mail:molinier@cnam.fr
}

\begin{abstract}
Resumo
A psicodinâmica do trabalho se define como a análise dos processos psíquicos mobilizados pelo encontro entre um sujeito e os constrangimentos da organização do trabalho. Nos anos 1980, as pesquisas realizadas nos meios de trabalho masculino permitiram descobrir a existência de estratégias coletivas de defesa contra o sofrimento no trabalho. A partir de 1988 iniciou-se um importante trabalho interdisciplinar com as sociologias do trabalho. Trata -se de saber se a psicodinâmica do trabalho era heurística para analisar igualmente as situações das mulheres no mundo do trabalho e de reexaminar os conhecimentos preexistente, sobre o sofrimento dos homens no quadro de uma problemática sexuada. 0 artigo relata os principais determinantes que conduziram a criar as relações sociais de sexo e de seu desafio, a divisão sexual do trabalho, uma dimensão central da pesquisa clínica, a teoria e a metodologia em psicodinâmica do trabalho. Um ponto importante do artigo é a situação das enfermeiras a partir da qual são constituídos os principais conhecimentos sobre as relações entre saúde e trabalho do lado das mulheres.
\end{abstract}

Palavras-chave

Psicodinâmica do trabalho, relações sociais de sexo, sofrimento no trabalho, estratégias coletivas de defesa.

\section{Psychodynamics of work and sex social relationships. An interdisciplinary itinerary. 1988-2002}

\begin{abstract}
The psychodynamics of work is defined as the analysis of psychic processes mobilized by the gathering of a subject and the work organization constraints. In the 80s, the researches conducted in male workplace environments allowed to uncover the existence of collective defense strategies against suffering at the work. As from 1988, an important interdisciplinary work with work sociologies was launched. It is concerned with knowing whether the psychodynamics work was heuristic to equally analyze the situations of women at work and to reexamine the preexisting knowledge on men suffering in a sexualized problematic framework. The paper reports the main determinants which led to the establishment of sex social relationships and its challenge, the sexual division of work, a central dimension of the clinic research, the theory and methodology in workplace psychodynamics. An important issue in the paper is the situation of nurses, from which is constituted the main knowledge on the relations between health and work on the women's side.
\end{abstract}

\section{Key words}

Work psychodynamics, sex social relationships, suffering at work, collective defense strategies. 


\section{INTRODUĈ̣̃O}

A psicodinâmica do trabalho foi iniciada por Christophe Dejours no fim dos anos 1970. Seu tema é a análise da relação entre saúde mental e trabalho. Depois nos interessamos mais particularmente pela dinâmica do sofrimento e do prazer na situação de trabalho. O modelo de homem provém da antropologia freudiana, a partir da qual se considera que o sujeito aborda o mundo do trabalho com o conjunto daquilo que ele é e daquilo que procura alcançar. A consciência que ele tem destes fatos é confusa e parcial. Quando esta busca pessoal pode ser atingida em situação de trabalho, então o trabalho tem um papel importante na realização de si. Quando a organização do trabalho faz obstáculo à elaboração do sofrimento e a sua transformação em prazer, então o trabalho pode ser prejudicial para a saúde mental. Não há neutralidade do trabalho defronte à saúde mental.

Durante os anos 1980, a relação saúde mental-trabalho foi conceitualizada principalmente por homens, a partir de investigações clínicas realizadas junto aos trabalhadores masculinos que exerciam atividades perigosas (pilotos de caça, operadores e engenheiros da indústria de processo contínuo, operários da construção civil) (DEJOURS, 1980). O corpo teórico da psicodinâmica do trabalho desenvolveu-se a partir da descoberta, nestes meios de trabalho,

de estratégias coletivas de defesa, isto é, de formas de cooperação para lutar contra o sofrimento no trabalho, mais precisamente contra o medo gerado pelos riscos da atividade. Pode-se mostrar que estas estratégias coletivas de defesa eram mais eficazes para pre-

servar a saúde mental que as estratégias individuais, mas elas traziam distorções de comunicação, impedindo que fosse pensado e discutido aquilo que, no trabalho, seria difícil suportar psiquicamente. Aparecia uma nova forma de racionalidade da ação, a racionalidade subjetiva ou racionalidade pática da ação, orientada para a sobrevivência e a saúde, que permitia interpretar de outra maneira "condutas insólitas" ou de "resistência à mudança" julgadas até como irresponsáveis ou contraprodutivas.

Os fundamentos teóricos da disciplina e suas primeiras descobertas empíricas foram também estabelecidos num quadro de referência ao masculino-neutro, onde a questão era saber se a teoria em psicodinâmica do trabalho seria adequada para compreender também as situa- ções vividas pelas mulheres. A descoberta das diferenças homem/mulher não são feitas no campo, a despeito das primeiras investigações realizadas junto às pessoas que trabalham com cuidados à saúde, na maioria mulheres como as enfermeiras, auxiliares, atendentes. Fomos levadas a constatar que não encontrávamos, neste coletivo de trabalhadores, estratégias coletivas de defesa semelhantes àquelas descritas na petroquímica ou na construção. Deduzimos, na época, a ausência de cooperação defensiva entre estes profissionais, prova que não se encontra sempre aquilo que se procura.

Em 1988, na época do seminário interdisciplinar "Plaisir et souffrance dans le travail", Danièle Kergoat e Helena Hirata lançaram uma verdadeira "bomba", colocando a questão se a psicodinâmica do trabalho podia "tratar das relações sociais de sexo" (HIRATA, KERGOAT, 1988), demonstrando que a problemática das relações sociais de sexo era transversal ao conjunto do campo social, portanto ao conjunto dos campos disciplinares, relativo aos homens assim como às mulheres e, ao trabalho assalariado como ao trabalho doméstico. Elas estão na origem de remanejamentos teóricos e, conseqüentemente metodológicos, de envergadura que tinham, e continuam a ter, um impacto decisivo sobre o conjunto do programa científico em psicodinâmica do trabalho.

\section{uando a organização do trabalho faz obstáculo à em prazer, então o trabalho pode ser prejudicial para a saúde mental. Não há neutralidade do trabalho defronte à saúde mental.}

\section{Psicanálise e divisão sexual do trabalho: uma teoria implícita}

Do ponto de vista psicanalítico, consideramos que as diferenças psíquicas entre os homens e as mulheres encontram sua origem na idade precoce da psicosexualidade, portanto bem antes do encontro com o trabalho. Desta perspectiva, o status teórico da divisão sexual do trabalho é de pouca importância. É subentendido que este é, pode-se dizer, o prolongamento social destas diferenças e se justifica pelo fato destas diferenças. Esta concepção naturalista e harmoniosa da divisão sexual do trabalho existe, aliás, em sociologia (cf. o funcionalismo de Parsons). Sem dúvida as injustiças sociais deverão ser corrigidas, mas a divisão sexual do trabalho não será 
abolida, pois ao oferecer tarefas diferentes aos homens e às mulheres, ela estará em ressonância simbólica com suas orientações diferenciadas em matéria de realização de si. Para explicar por que certas pessoas fazem uma escolha profissional atípica, sem colocar em questão a complementaridade entre os sexos, a noção de bissexualidade psíquica pode ser utilizada como uma variável de ajuste afim de dar conta das situações de exceção. Cada um(a) teria em si uma parte feminina e uma parte masculina, com uma dosagem diferente segundo os indivíduos. Uma solução teórica aparentemente menos estigmatizada para as mulheres que a interpretação de suas ambições profissionais em termos de "reivindicação fálica" ou de "complexo de masculinidade". Seria também menos imediatamente homofóbica face aos homens que exercem tarefas femininas. Todo este arcabouço, em grande parte implícito, foi colocado em questão pelos sociólogos do trabalho através de sua categorização de classe e de sexo.
Esta forma de divisão social tem dois princípios organizadores:

- o princípio da separação (tem trabalhos de homens e trabalhos de mulheres);

- o princípio hierárquico (um trabalho de homem "vale" mais que um trabalho de mulher)" (KERGOAT, 2001, p. 89)

Segundo a autora, se os dois princípios organizadores se encontram em todas as sociedades estudadas, por outro lado, um aspecto fundamental é que constatamos uma grande variabilidade das modalidades da divisão sexual do trabalho, no espaço e no tempo. Nesta perspectiva, as diferenças constatadas entre as práticas dos homens e das mulheres são devidas a construções sociais, e não relevam uma casualidade biológica. Esta construção social, tem uma base ideológica (o naturalismo) mas também e antes de tudo material - " quer dizer, a 'mudança de mentalidade' não se fará jamais espontaneamente se ela ficar desconectada da divisão do trabalho concreta. "(KERGOAT, 2000, p. 40). Isto implica uma conceituação rigorosa do trabalho que "desconstrói" a clivagem trabalho-fora do trabalho e não desassocia a relação de produção da relação de reprodução. Por outro lado, e se trata de um importante aspecto, a relação social do sexo é um conceito analítico. Daniele Kergoat insiste sempre sobre o caráter de abstração, isto para ficar atento contra uma análise solipsista da complexidade

\section{A divisão sexual do trabalho: 0 desafio das relações sociais de sexo}

Segundo Danièle Kergoat, a relação social do sexo é uma tensão que estrutura e atravessa o conjunto do campo social e desafia certos fenômenos sociais entorno dos quais se constituem grupos de interesses antagônicos. A relação social do sexo se fundamenta primeiramente e antes de tudo em uma relação hierárquica entre o grupo social dos homens e o grupo social das mulheres. Estes grupos estão em tensão permanente em torno de um desafio central, o trabalho e suas divisões.

“A divisão sexual do trabalho tem por característica a afetação prioritária dos homens à esfera produtiva e das mulheres à esfera reprodutiva como que simultaneamente a captação pelos homens das funções com um forte valor agregado (políticas, religiosas, militares, etc.) das práticas sociais. Se a relação social de sexo é heurística para pensar as práticas sociais, os desafios e suas evoluções, não pode ser isolada das outras relações sociais. Imbricação e recobrimento parcial das relações de classe e de sexo são conceituadas não só em termos de hierarquia mas de co-extensividade.

Trabalho, subjetividade e determinismos sociais

A partir dos fundamentos epistemológicos aparentemente também distantes, como explicar que o encontro entre a psicodinâmica do trabalho e os sociólogos do trabalho poderia apesar de tudo acontecer?

As relações sociais de sexo representavam o nó cego da psicodinâmica do trabalho. Mas a problemática do prazer e do sofrimento no trabalho foi sendo construída recusando a "tentação" psicossociológica, isto é, a tese da articulação entre o indivíduo e o social, em proveito de uma concepção dinâmica das relações entre sujeito e 
sociedade. Entre a cena do fantasma e a experiência do trabalho (tendo como exemplo o sonho da ausência de gravidade e a profissão do piloto de caça), havia a materialidade dos constrangimentos da organização do trabalho (DEJOURS, 1980). Isto não se inscrevia na continuidade da história pessoal, mas se impunha independentemente da vontade do sujeito. A experiência do trabalho não repetia a história infantil. Também, problematizar as relações dinâmicas entre o sujeito e o trabalho implicava em evitar um duplo obstáculo:

- Por um lado, não fazer o impasse sobre o peso dos determinismos sociais e seu heteronômio com relação à psicologia individual. Em suma, deve-se adotar uma verdadeira teoria social.

- Por outro, não ceder a uma outra "tentação", aquela de uma ciência do homem sem subjetividade, de acordo com estes determinismos um peso tão esmagador que o sujeito é reduzido a ser um simples reflexo social, uma marionete sem espessura psíquica e portanto sem liberdade. De qualquer forma, a análise das relações dominante-dominado(as) se reduzirá pura e simplesmente a uma teoria de alienação, inapta a pensar os processos de emancipação.

A sociologia das relações sociais de sexo dá um estatuto privilegiado ao antagonismo, ao conflito. "As relações sociais não são para mim o determinismo, escreve Danièle Kergoat, mas ao contrário são uma maneira de pensar e de trabalhar a liberdade" (HIRATA, KERGOAT, 1988, p. 140). Além disso, estreitamente ligado à questão da liberdade, o trabalho representa um desafio central nas duas disciplinas. Parece, retrospectivamente, que foi esta doutrina comum das relações entre determinismos e liberdade que tornou possível um trabalho interdisciplinar, fecundo para as duas partes. Kergoat e Hirata integraram no seu próprio trabalho teórico que os desafios em termos de emancipação não podem ser desvinculados dos desafios em termos de saúde mental, e que "não podemos pensar o trabalho, inclusive sociologicamente, sem considerar a subjetividade" (KERGOAT, 2001, p. 89).

\section{Uma primeira etapa: reconsiderar o sofrimento dos homens}

No seminário "Plaisir et souffrance dans le travail " Christophe Dejours contribui escrevendo: " Cada sofrimento será, seguindo as teses sociológicas aqui expostas, sexuado (...). Certos sofrimentos são masculinos, outros femininos. Eles não são similares, porque as situações de trabalho que os produzem não são as mesmas" (HIRATA, KERGOAT, 1988, p.167)

A primeira etapa reconsiderou o sofrimento no trabalho dos homens. Danièle Kergoat possibilitou uma nova leitura, uma leitura sexuada, das estratégias coletivas descobertas entre os homens, salientando a importância da virilidade social nas suas estratégias. É o que ela indica sobre os caminhoneiros da fábrica Bulledor, onde o responsável de recursos humanos os comparava a "uma horda de cavalos selvagens" (HIRATA, KERGOAT, 1988, p. 153). O que a sensibiliza é de um lado um julgamento positivo proferido pela hierarquia sobre um grupo percebido pela chefia como rebelde. Por outro lado, os motoristas julgavam positivamente seu trabalho, ainda que a duração e as condições sejam duras. A exaltação viril não tem função de "compensar" a exploração sofrida devido às relações de classe? Esta questão terá forte incidência sobre a conceituação das estratégias coletivas de defesas.

\section{- m essencial, um homem, um "verdadeiro", deve multiplicar as demonstrações de coragem para conseguir convencer seus companheiros e compartilhar os mesmos riscos, que ele domina e despreza o medo.}

A dimensão coletiva destas estratégias apareceu de maneira típica na profissão da construção civil. É, principalmente, a de lutar contra o medo gerado pelo trabalho opondo coletivamente uma recusa de sua percepção. $\mathrm{Na}$ construção desta recusa, a virilidade social tem um papel preponderante. Em essencial, um homem, um "verdadeiro", deve multiplicar as demonstrações de coragem para conseguir convencer seus companheiros e compartilhar os mesmos riscos, que ele domina e despreza o medo. A exaltação viril não oferece somente uma "compensação" narcísica à exploração, ela se constitui em uma verdadeira ideologia defensiva que, logo que ela é compartilhada por todos os membros de um coletivo de trabalho, interdita a expressão de medo e mais amplamente a de sofrimento no trabalho. Aquele que sofre deve se calar e/ou partir, senão ele passa por um fraco, um "afeminado", uma "mulher". Entre os assalariados, como no espaço privado, as atividades suscetíveis de fragilizar a posição viril, por que elas confrontam a vulnerabilidade humana, são ocupadas pelas mulheres, de preferência sem falar com os homens, sob pena de se expor a seu mau humor, ou ainda pior (MOLINIER, 1996). A recusa do sofrimento dos homens 
aparece também como um apoio psicológico fundamental na análise combinada das relações sociais de produção e de reprodução, e como um dos princípios organizadores das práticas sociais, notadamente das lutas sindicais.

Em 1998, C. Dejours dará um passo suplementar ao mostrar que a virilidade "não anestesia" somente a percepção do medo, mas também o sentido moral (DEJOURS, 1998). A análise do "cinismo viril" na organização contemporânea coloca as formas de racionalização defensiva, em particular do lado dos executivos, para justificar a sua própria participação na injustiça social. Todos os termos que são associados à virilidade se estabelecem na hierarquia dos valores e são suscetíveis de adquirir uma grandeza, mesmo se infligir um castigo ao sofrimento ou à injustiça para com outros. Um homem, um "verdadeiro", não terá crises. Em nome da coragem viril, o mal feito pelos homens é mais facilmente justificado que aquele cometido pelas mulheres e o bem que elas fazem alcança o mesmo valor daquele dos homens.

\section{2- eu, eи não sou invejosa;}

As premissas colocam em visibilidade a recusa do indivíduo-operário de se identificar pertencente a um grupo de "mulheres" julgado pejorativamente segundo os estereótipos sexistas da ideologia dominante. A idéia forte é que formalmente a conclusão deveria ser:

\section{3- então eu não sou uma mulher.}

Na medida em que "eu não sou uma mulher" não é nem dizível nem mesmo pensável, "a constituição sexual do sujeito se encontra assim bloqueada ao nível de suas representações" e parece ser um impasse (KERGOAT, 1988, p. 110).

As operárias não podem, como mulheres, se constituir em um "sujeito social". Quais são as conseqüências de uma falta de identidade social sobre a identidade individual? Como será para as mulheres qualificadas? O estereótipo da "inveja", ao inverso dos "valores" viris mobilizados pelos hos operárias não podem, como mulheres,
se constituir em um "sujeito social".
Quais são as conseqüências de uma falta de
identidade social sobre a identidade individual? Como será para as mulheres qualificadas?

\section{As operárias e o silogismo}

\section{do sujeito sexuado feminino}

Existem coletivos de profissões femininas? Das formas de cooperação específicas e das formas de cooperação defensiva feminina? Segundo Danièle Kergoat, o coletivo das operárias existe apenas em período de luta e o grupo de operárias aparece no cotidiano inteiramente fragmentado, definido pela representação dada pelas operárias, "como um agregado atravessado por uma intensa concorrência interindividual (a solidariedade será a condição exclusiva do grupo de homens ou ao menos do grupo misto)". O problema da "inveja" volta como um leitmotiv em quase a totalidade das entrevistas.

Em termos de reprodução dos esteriótipos sexuais, como nos discursos sobre a "inveja", Kergoat decida dar importância ao que "as prórpias operárias reconhecem", formalizando-os por um silogismo (KERGOAT, 1988):

1- todas as mulheres são invejosas (têm medo do chefe, são fofoqueiras, etc.);

\section{Para trabalho diferente, sofrimento diferente: a compaixão das enfermeiras}

Para tentar responder a estas questões, é preciso encontrar uma situação que autorize a comparação com as situações de trabalho masculinas que permitiram construir os conhecimentos em psicodinâmica do trabalho. Prescrita por homens (médicos e administradores), a profissão de enfermeira foi inventada, exercida e estabelecida por uma maioria de mulheres, em todos os níveis hierárquicos. Ainda que implique em formas de comando e cooperação, técnica é uma dimensão importantes trata-se de um trabalho que confronta o medo (contaminação, erro, violência...). Mesmo que comporte similitudes com situações masculinas, o trabalho de enfermagem é também bem diferente: explicitamente orientado para atender aos outros e aliviar o sofrimento psíquico, ele aparece, por estas razões, fortemente indexado à identidade feminina.

Para investigar as situações do trabalho de enfermagem, a solução foi privilegiar um construtivismo metodo- 
lógico. Suspendemos deliberadamente a questão do saber se os homens e as mulheres eram, por natureza, diferentes. Fiéis às opções metodológicas da psicodinâmica do trabalho, escolhemos como eixo de análise o conflito entre o sujeito e os constrangimentos da organização do trabalho. Mas este conflito foi redefinido no contexto de uma problemática integrando a divisão sexual do trabalho como uma dimensão estrutural e central na relação subjetividade-trabalho.

A confrontação com o sofrimento de outro é a fonte de um sofrimento específico que é a compaixão (sofrer com). Quais são as principais descobertas sobre este sofrimento?

A experiência dos alunos de enfermagem se instaura sob a influência do medo e do desgosto, combinado com a tentação de demolir os muros e evitar a confrontação com os doentes. Não é a compaixão que está em primeiro plano, mas os comportamentos de recusa. A compaixão é um processo psíquico desencadeado pela obrigação determinada pelo confronto com os doentes, mesmo quando não se tem vontade, e que só se elabora graças a um grande esforço coletivo. A compaixão é fruto de uma construção social.

De um lado, a relação subjetiva com o outro é fortemente impregnada de ambivalência; estamos ocupadas com pessoas cujo estado de degeneração física e mental suscita angústia, desgosto e medo. De outro, a organização do trabalho hospitalar, notadamente através de seus constrangimentos temporais, tende a passar a humanização dos cuidados para um segundo plano com relação às dimensões técnicas do trabalho. Mas a instrumentalização da atividade é vivida como insatisfatória do ponto de vista dos valores, do sentido da profissão. Trabalhar bem é construir o melhor compromisso entre eficácia técnica e compaixão. Tal compromisso é necessariamente imperfeito, mas ele pode ser julgado aceitável. A qualidade das arbitragens coletivas é decisiva, tanto para evitar a desumanização dos cuidados como os riscos de transgressões individuais (por exemplo, não colocar luvas de proteção por compaixão aos pacientes em estado terminal da AIDS. CARPENTIER-ROY, 1991). As dimensões ambíguas da afetividade estão na realidade sempre presentes numa atividade aonde as relações podem alcançar uma real intensidade. Por um processo de deliberação, o pessoal de enfermagem estabeleceu uma fronteira coletiva entre, como elas dizem, "a mulher" e a "profissional", para não "misturar tudo". A importância que as enfermeiras conferem a esta fronteira, como garantia de sua saúde mental, sugere que, em suas representações, a identidade feminina e a identidade profissional não se recobrem completamente, e a confusão entre as duas será fonte de sofrimento.

"No começo, como enfermeira, eu interpretava mal as falas que vinham dos homens, tipo: você tem a mão doce (...). Eu quero ser reconhecida, como enfermeira, não só como mulher. (...) Você sabe, quando você é uma garota, você tem sempre medo dos contatos porque podem ser vistos como uma agressão física: não pode me tocar porque tem a intenção de mexer no meu corpo, isto eu não suporto. Aí é o momento aonde eu ainda preciso me afirmar tanto como profissional como mulher." (KERGOAT, 2001, p. 95).

\section{"Todas as mulheres são fofoqueiras": esteriótipo sexual ou estratégia coletiva de defesa?}

As enfermeiras dissociam com insistência o "ser-mulher" de seu profissionalismo, insistência sem equivalência do lado dos homens. Os valores da compaixão jamais são por elas considerados como valores especificamente femininos (vs os valores viris) ${ }^{1}$. Suas estratégias coletivas de defesa são também opostas às estratégias viris: elas não podiam ser entendidas num modelo teórico "androcentrado". É a tonalidade particular das discussões entre o pessoal que se ocupa dos cuidados à saúde que faz aparecer as especificidades da cooperação defensiva, sob condição de manter uma distância dos estereótipos sexuados, a fim de escutar outra coisa que não fofoca da «mulherada» ou «das descerebradas».

\section{A $s$ enfermeiras dissociam com insistência A o "ser-mulher" de seu profissionalismo, insistência sem equivalência do lado dos homens.}

A negação de sua própria vulnerabilidade deixava as enfermeiras insensíveis ao sofrimento, colocando em xeque a eficácia e mesmo o sentido do trabalho. As discussões entre elas visa elaborar o sofrimento gerado pelo trabalho hospitalar sem contrapor uma negação. Mas esta elaboração coletiva é tão ambígua quanto a realidade que ela tenta subverter. As enfermeiras consagram um tempo significativo para discutir entre elas, de preferência tomando um cafezinho. Estes momentos de convívio são necessários para a coesão da equipe e a qualidade do trabalho, como para a boa saúde mental, mas tendem a desaparecer à medida que o trabalho se intensifica. Durante essas discussões informais, as mu- 
lheres trocam informações preciosas para acompanhar o trabalho, e também expressar seus diversos sentimentos, as dúvidas, a inquietação, a impotência, a atração ou a aversão. O tom de suas conversas pode parecer insólito, às vezes chocante para pessoas de fora. As situações descritas são geralmente patéticas, portanto é o bom humor que rege. Cada uma se esforça em "desdramatizar" as situações vividas, empregando façanhas inventivas e fantasias para deixar o cotidiano mais agradável e divertido. Para dizer de uma outra forma, trata-se de inventar um conjunto de recursos simbólicos que permita deixar o mundo mais vivível sem portanto eliminar o sofrimento. Para tanto, elas zombam dos doentes, dos chefes e dos médicos, mas sobretudo elas zombam de si mesmas, "frágeis-mulheres". A dimensão da auto ironia frente à própria vulnerabilidade é a componente essencial das defesas "femininas". $O$ sentimento de vulnerabilidade é congruente com a feminilidade. Ao contrário, zombar de suas próprias fraquezas, de suas próprias perdas, é inconcebível na perspectiva viril. Existe uma "sexuação" das defesas. Evidentemente isto não se dá porque as mulheres são dotadas, desde o nascimento, da capacidade de reconhecer em si suas próprias fraquezas e de tolerá-las nos outros.

Estas estratégias de "domesticação" do real são contingentes e só se elaboram porque existe um coletivo de regras de enfermagem. Ora, a perenidade do coletivo é contribuinte do desejo de dividir sua experiência do trabalho com os colegas. Isto implica em estar de acordo com o que se faz. A dificuldade do trabalho compassivo assinala a entrada do sofrimento ético. É o caso, para dar um exemplo, quando os trabalhadores do hospital têm o sentimento de ser antes de qualquer coisa avaliados não pela qualidade de seu cuidado, mas por sua prontidão em " esvaziar as camas" ou as "rentabilizar". Eis, tipicamente, o tipo de situação suscetível para quebrar a palavra no seio do coletivo e provocar "descompensações" psicopatológicas. Estas interferem logo que o sujeito não consegue mais trabalhar conforme seus valores; logo que ele tem o sentimento de desenvolver um trabalho indigno, nefasto para o outro. Uma tarefa que ele tem vergonha e que ele não quer, portanto, colocar em deliberação com seus colegas. Não é a compaixão que é patogênica mas a impossibilidade crônica de lhe dar uma saída criativa no cuidar.

Quais são as formas de compensação das pessoas que trabalham com cuidados aos outros? Qual é a sua freqüência? Os médicos do trabalho que atuam em hospitais serão os melhores para responder a estas questões, sabendo que as relações entre sofrimento no trabalho e doença não mantém relações causais: depressões, suicídios, passagens ao ato violento para uns, aparecimento de diver- sas doenças somáticas para outros. Nossos estudos sugerem que entre o drama da doença e a subversão coletiva do sofrimento, uma alternativa muito utilizada é a das estratégias individuais de defesa.

\section{Duas estratégias individuais típicas: a mudança e 0 ativismo}

Em um estudo realizado com chefes de enfermagem que sofriam de fadiga ${ }^{2}$ por excesso de trabalho, na medida em que elas estimam que não podem trabalhar conforme seus valores, Seria mais sábio pedir rapidamente uma mudança de cargo ou de setor do que se desgastar em conflitos estéreis e inúteis com os chefes de serviço e com a administração (MOLINIER, 2001). De fato, partidas e mudanças intervêm logo que as pessoas compreenderam que não tinham poder para modificar a situação ${ }^{3}$. Em suma, as estratégias de mudança (às vezes demissão) intervêm depois de tentativas abortadas de resistência ou de rebelião, tentativas freqüentemente custosas no plano pessoal e cujo insucesso é doloroso de elaborar. Partir significa a recusa de se tornar cúmplice do sistema e a vontade, como dizem as chefes de enfermagem, de "salvar sua pele" ${ }^{4}$. O pedido de mudança (ou a demissão) ocorre frequientemente após uma fase de ativismo. $\mathrm{O}$ ativismo é uma estratégia, clássica no meio hospitalar, que consiste em querer concluir sua tarefa integralmente, notadamente a não sacrificar a humanidade dos cuidados, sem contar suas horas de trabalho. $\mathrm{O}$ ativismo privilegia então o sentido do trabalho. Mas é uma estratégia a curto prazo que ocorre sobre a diminuição da vida pessoal e sobre o esgotamento profissional, o qual numerosos trabalhadores que cuidam de outras pessoas tentam amenizar usando automedicação.

Se o ativismo é explorado pela organização do trabalho, ele não é reconhecido nem recompensado. Quando as pessoas que cuidam de outras são usadas, consumidas e se tornam, portanto, em parte inaptas para sua função, elas são estigmatizadas por seus colegas, que as enquadram como "braços quebrados". O ativismo é raramente uma estratégia coletiva ${ }^{5}$, ele é fonte de conflito e de divisão no seio das equipes, entre aquelas que não contam suas horas, aceitam fazer substituições nos seus dias de descanso, e aquelas que tentam proteger sua vida privada, fazendo respeitar seus direitos. Estas devem compor com os constrangimentos (mono)parentais, ou simplesmente vivem em "sobrecarga" por excesso de trabalho. Na medida em que as equipes das pessoas que cuidam sejam formadas por mulheres da classe média sujeitas a dupla tarefa, tem uma função primordial.

Pela diferença com o sofrimento gerado pelo trabalho de enfermagem, o sofrimento gerado por sua "conciliação" com o trabalho reprodutivo é visto como um proble- 
ma individual e não como uma dificuldade que poderia ser socializada e superada coletivamente. Isto aparece claramente nos estudos realizados com chefes enfermeiras, quando elas não conseguem "conciliar" o papel maternal e conjugal com o seu trabalho, o que pode sob a ótica dos constrangimentos da organização do trabalho parecer, ao menos para nós pesquisadores, como uma missão impossível. Portanto não é a organização do trabalho que elas remetem em questão, mas a elas mesmas (ou àquelas que não conseguem). "Más profissionais" e "más mães" é "sua culpa": elas erraram em querer fazer carreira. Esta personalização de suas dificuldades as conduz a ficarem sozinhas, no silêncio e na culpa, com inteira responsabilidade. Enfim, quando as enfermeiras esgotadas tentam levar as suas dificuldades para aqueles que decidem, elas estão num estado de excitação, esgotamento emocional, confusas. Seu estado é, em geral, julgado como patológico pelo interlocutor. Nelas estaria todo o problema, na sua atividade, na sua " devoção" ou na sua fragilidade (MOLINIER, 2000).

Abordamos, aqui, um dos principais problemas. Quem compadece? A "mulher"? ou a "profissional"? A compaixão não está incluída como um trabalho, ela é naturalizada, confundida com a feminilidade. À medida dos interesses defensivos dos que decidem, a compaixão é idealizada no registro da sensibilidade feminina ("as mulheres são formidáveis"), ou racionalizada pejorativamente como pieguice (as mulheres têm "crises"). Em seguida, nós vimos que é sobre um modo aonde a compaixão não é jamais desassociada do humor e da autogozação que as enfermeiras contam sua vivência do trabalho através do que é uma arte de viver o sofrimento. Compreendemos que este modo de narração tão particular seja difícil de socializar fora do coletivo delas: é inaudível a partir da posição de negação viril. Todavia, o déficit de visibilidade do trabalho compassivo não é unicamente devido à negação de realidade dos que decidem. Para ser eficaz, o trabalho compassivo deve se tornar invisível antecipando com relação às necessidades do outro, em termos de conforto, de escuta, de segurança, de presença, etc. Como reconhecer o trabalho, aonde esperam a autenticidade de um gesto de simpatia? Os saber fazer compassivos são discretos (MOLINIER, 2000). Para as enfermeiras, uma vez estabelecida, a compaixão se experimenta espontaneamente, como um sofrimento ...., ela torna-se uma relação com o mundo, uma postura, vivida como natural.
Volta sobre a continuidade sujeito sexuado-sociedade

As descobertas realizadas junto às enfermeiras, de um lado, e o estatuto da negação do real nas estratégias defensivas viris, de outro lado, confrontam a tese da continuidade entre a identidade sexual e a divisão sexual do trabalho? Segundo Roiphe e Galenson (1981), as observações sistemáticas feitas de crianças dos dois sexos, entre quinze e vinte e quatro meses, sugerem que a negação será uma postura física enraizada bem cedo no desenvolvimento infantil do menino, enquanto que as meninas serão "preparadas" ao reconhecimento do real do corpo e sua vulnerabilidade ${ }^{6}$. É numa idade não muito precoce que os teóricos da ética do cuidar (ethics of care) instituem a diferença entre o "eu relacional" das meninas e o eu abstrato dos meninos (CHODOROW, 1978, GILLIGIAN, 1982). Sem dúvida, a transmissão das identidades e dos "papéis do sexo" se enraízam nas interações precoces, antes do trabalho, entretanto, como sabemos, com importantes variações entre os indivíduos. Mas, nos exemplos, parece que aquilo que se esboça na infância é em seguida profundamente modificado pelo encontro com o real do trabalho e muito pouco compreendemos sobre as vicissitudes da identidade (pedestal da saúde mental) na idade adulta sem referência à materialidade do trabalho.

\section{$\square$ ela diferença com o sofrimento gerado pelo trabalho de enfermagem, o sofrimento gerado por sua "conciliação" com o trabalho reprodutivo é visto como um problema individual e não como uma dificuldade que poderia ser socializada e superada coletivamente.}

Assim, a negação da realidade não é única (e a melhor) forma de se defender contra o sofrimento gerado pelas atividades exercidas por uma maioria de homens. Estas atividades não precisam ser efetuadas de maneira viril para serem bem-sucedidas. Parece, com efeito, que uma minoria entre as mulheres não mobiliza sempre exatamente as mesmas fontes psíquicas que os homens, como Lívia Scheller mostrou sobre as condutoras de ônibus (SCHELLER, 1996).

Além do mais, mesmo que nas atividades "masculinas" as mulheres trabalhem em parte diferentemente dos homens, não é sempre a primeira intenção. Mas sobretudo porque as mulheres tentam empregar os métodos viris, aqueles que funcionam para os homens, são 
freqüentemente a seu prejuízo e insucesso. Isto aparece nitidamente num estudo de Joan Cassell sobre as cirurgiãs (CASSELL, 2000). Estas devem enfrentar expectativas específicas, para a maioria implícitas, da parte de suas hierarquias, colegas e subordinados. Em particular, se espera das mulheres no posto de comando que elas façam prova de firmeza como os homens, mas que elas também estejam mais à escuta dos outros, mais "humanas", diriam trivialmente. Isto, as cirurgiãs não aprendem nem na faculdade, nem observando os mestres, elas descobrem em situação de trabalho. É então, em seu corpo, sem ter antecipado primeiro, que elas são conduzidas a experimentar defensivamente formas de relações profissionais, de autoridade e de gestão (mais "compreensível") diferentes das dos homens, assim como outras defesas (MOLINIER, 2003). ça que resulta de uma estratégia kaporalista não beneficia a "ascensão viril", pois retorna num "valor", uma vez que atinge o registro da identidade. Se for para renovar a reflexão moral apoiando-se sobre a experiência concreta das mulheres, assim como a censura ética da solidão, é necessário ter-se em conta a base material desta experiência, isto é, a divisão sexual do trabalho, as relações sociais de classe e de sexo, assim como os conhecimentos sobre as estratégias coletivas de defesa. À revelia, as auxiliares de enfermagem que se defendem da fadiga e da humilhação pelo kaporalismo vivem o risco de ser duplamente estigmatizadas, julgadas "malvadas" tanto como profissionais como mulheres (a indiferença ao outro e a violência são antinômicos com a definição da feminilidade "relacional").

\section{A dupla centralidade do trabalho e da sexualidade}

A identidade sexual se esboça durante a infância. Este primeiro pilar é colocado em questão não somente pelas primeiras experiências amorosas mas também, de uma maneira decisiva, pela experiência do trabalho. É no momento da adolescência, período chave do desenvolvimen-
Enfim, as mulheres que exercem atividades "femininas" não estão sempre na medida de reconhecer o real. É o caso quando elas se defendem de perceber seu trabalho como degradante para a sua própria dignidade, em particular quando ele consiste em limpeza sem descanso (e sem reconhecimento) dos dejetos corporais e porcarias dos outros. Assim, podemos identificar, em certos coletivos de atendentes de enfermagem ideologias defensivas da profissão ${ }^{7}$ chamadas de Kaporalisme (ou ideologia da ordem ao mérito) que consiste em fazer uma triagem entre:

- os (alguns) pacientes que merecem a compaixão e serão tratados como pessoas sem restrições (aqueles que cooperam ativamente e manifestam a gratidão);

- e aqueles que serão tratados como subprodutos da espécie humana, como "coisas", porque eles diminuem o trabalho e contribuem com a penosa tarefa sem manifestar gratidão: tipicamente os doentes mentais, que "não têm mais sua cabeça" os drogados e os alcoólatras, que "terão aquilo que eles merecem", ou as mulheres no dia seguinte da tentativa de suicídio, que "fazem drama" (MOLINIER, 1966).

Assinalemos que tal manobra coletiva contra a perda da auto-estima, devastadora para os doentes que são o alvo, modifica muito superficialmente o sentimento de se deteriorar numa tarefa indigna. O maltrato, ou a mínima indiferen- to, que entram em conflito os dois problemas, o da escolha profissional (vetorização inconsciente $\rightarrow$ sujeito) e as incidências da situação de trabalho sobre a vida psíquica e afetiva do adulto (vetorização sociedade $\rightarrow$ sujeito (DEJOURS, 1996). Isto leva a postular uma "dupla centralidade", a da sexualidade e a do trabalho, no funcionamento psíquico e na construção da saúde. Esta discussão se iniciou desde 1988 em um artigo consagrado essencialmente, como indica seu título, ao "masculino entre sociedade e sexualidade" (DEJOURS, 1988).

É raro que o sujeito, quando entra no mundo do trabalho, seja suficientemente maduro e seguro de sua identidade sexual para pretender ser aceito pelos outros como amável enquanto homem (ou enquanto mulher) ${ }^{8}$. É por isso que nos encontros entre o sujeito masculino e os constrangimentos deletérios das situações de trabalho, $o$ risco de captura da identidade masculina pela virilidade defensiva é real. O homem virilizado escora seu funcionamento mental e social a partir de representações estereotipadas e imagens prontas, também é pouco acessível aos remanejamentos psíquicos, fragilizado não somente por abordar o reencontro erótico com uma mulher alter ego, mas também por elaborar ao longo da vida as situações de ruptura, em particular as demissões ou a aposentadoria.

Do outro lado da relação social de sexo, para designar a posição feminina encravada, isto é alienada na submis- 
são, Dejours cria o neologismo de "mulheridade". Entre virilidade e "mulheridade", a identidade sexual das mulheres que trabalham em profissões tradicionalmente masculinas se dá sob grande tensão. É o caso de Mulvir, uma jovem analisada em psicoterapia por Dejours (1996). Ela, recusando repetir o destino maternal frustrado (mulheridade), deseja entrar num trabalho interessante e qualificado, o de técnica-eletricista. Mas, no seu meio social, não há mulher que represente um modelo de emancipação profissional e sexual. E no seu meio de trabalho exclusivamente masculino, ela deve consentir em aceitar as estratégias coletivas de defesa e os trotes construídos pelos homens, com o risco de uma conseqüente virilização - "uma crise da identidade sexual com os problemas do uso do corpo erótico e a uma hesitação sobre a orientação sexual (homo ou heterossexual)" (DEJOURS, 1996, p. 25). Dejours mostra que, numa abordagem psicanalítica convencional, a sua própria antes da discussão com Kergoat e Hirata, a luta trágica da jovem contra a "mulheridade" será interpretada como uma reivindicação fálica e uma recusa típica da castração. Mulvir não é "um homem castrado", mas uma jovem mulher em busca da realização de si. A tomada de consciência das relações sociais da produção e da reprodução tem incidentes pesados em termos da orientação terapêutica. Em princípio, a terapia pode reforçar a "mulheridade", antes de tudo uma defesa que consiste em "fazer a mulher" para ser aceita e amar (Ver GRENIER-PEZÉ, 2000 e MOLINIER, 2003).

"Através da feminilidade a subjetividade se descolaria do esteriótipo social de dona de casa submissa a seu homem, como a masculinidade será a testemunha do caminho feito pelo sujeito para não se deixar reduzir ao machismo convencional (identidade de empréstimo)." (DEJOURS, 1966, p. 20). As vicissitudes deste "descolamento" não são interpretáveis sem referência ao trabalho. Isto é adquirido. Mas as aspas que são colocadas na "feminilidade" sugerem que se avança num terreno conceitual incerto. A discussão com os sociólogos tem um papel importante nesta indefinição conceitual. Esta posição teórica prudente me parece ser sempre devida, especialmente porque há um verdadeiro hiato entre as definições sociais (androcentradas) da feminilidade e a maneira como esta se apresenta no discurso feminino. Já explicamos longamente sobre a naturalização do trabalho compassivo na feminilidade social. Acrescentamos que em psicodinâmica do trabalho, a identidade sexual foi problematizada por Dejours em termos de reciprocidade entre os sexos (como aquilo que escapa a toda relação social). Desta maneira, a masculinidade se construiria no encontro erótico com as mulheres, ao contrário da tese romântica de Rousseau que defendia a feminilidade como fruto da iniciação sexual pelo homem (HABIB, 1998). Portanto, quando as mulheres dissociam a "mulher" da "profissional", esta parte delas mesmas que elas designam como a "mulher" é antes de mais nada a que deseja que seu corpo lhe pertença. Livre de se "ocupar dela mesma" como as esposas dos homens que trabalham em turnos dos quais falaremos mais tarde, livre de recusar ser tocada contra sua vontade, como a jovem enfermeira citada, livre para não se embrutecer nas respostas repetitivas às necessidades dos outros, como testemunham amplamente as auxiliares de puericultura e as assistentes maternais (CHAPLAIN, CUSTOS-LUCIDI, 2001). No discurso das mulheres, é a inalienabilidade do corpo que aparece como o vetor principal da identidade sexual. Inalienabilidade a ser conquistada antes de toda maneira de reciprocidade sexual e que implica a subversão das relações sociais de sexo.

As duplas virilidade-masculinidade, mulheridade-feminilidade não são então simétricas e não reenviam a uma tipologia das identidades sexuadas, mas formam uma rede conceitual topológica para pensar a complexidade dos destinos de identidades, entre sexualidade e trabalho, sem fixar ou definir a essência dos conteúdos da masculinidade ou da feminilidade.

\section{A saúde dos homens: uma construção do trabalho conjugal?}

Discursos e práticas da maioria das mulheres aparecem fortemente marcados, não porque será uma adesão pura e simples a seu estatuto de dominada, mas pela luta contra a mulheridade. Isto autoriza retomar a controvertida questão do "consentimento" das mulheres, a sua dominação, ao menos aonde elas não são constrangidas pela violência.

\section{A s relações de produção não podem ser analisadas independentemente das relações de reprodução}

\begin{abstract}
"Por que (a despeito das mudanças da atividade feminina) o trabalho doméstico é e continua a ser realizado no meio da família e do casal gratuitamente e "voluntariamente" pelas mulheres? Por que mesmo aquelas que têm uma "consciência de gênero" "consentem" em reproduzir esta relação assimétrica?", pergunta Helena Hirata (2002, p. 14). Abre-se aqui um novo programa de pesquisa interdisciplinar, apenas esboçado, que representa um desafio teórico (DEJOURS, 2001) e metodológico.
\end{abstract}


Eu evocarei brevemente uma recente pesquisa feita com mulheres de homens que trabalham em turnos numa indústria de processo contínuo (MOLINIER et al., 2001). Permitindo confirmar que as relações de produção não podem ser analisadas independentemente das relações de reprodução, e portanto que as investigações sobre o sofrimento no trabalho não podem ser desligadas dos desafios em termos de transformações das situações de trabalho, esta pesquisa poderia inaugurar uma nova era para os dispositivos metodológicos em psicodinâmica do trabalho. Com efeito, a contribuição das mulheres de homens que trabalham em turnos não se limita à execução das faxinas domésticas, se acrescentamos um trabalho psicológico onde o papel é fundamental na construção e na preservação da saúde do esposo. Guardiãs do sono de seus esposos, da regularidade das referências temporais da família, guardiã do seu par, a cooperação das mulheres no espaço doméstico é necessária ao desempenho dos trabalhadores em turnos. Aliás, estes dizem que um homem solteiro não teria muito tempo disponível. O modo de produção doméstico toma tanto tempo que a maioria das esposas renunciaram a um trabalho assalariado ou desejam parar de trabalhar. A suspensão, provisória ou definitiva, da atividade é o preço a pagar para a sua própria saúde e a estabilidade do casal, pensam elas. fissionalmente, o trabalho doméstico só é suportável quando realizado perfeitamente. O zelo doméstico é um meio de lutar contra "o endurecimento", dizem elas, para não dizer a depressão silenciosa, a preguiça em frente à televisão à tarde ou as voltas intermináveis nos supermercados. Para as mulheres dos engenheiros, elas mesmas super qualificadas, a parada da atividade profissional é transitória (os jovens engenheiros não ficam mais de 5 anos no trabalho). Todavia, para os operadores de base, parece que a sua saúde conta em grande parte sobre a escolha de uma mulher sem ambições de carreira pessoal. Portanto, sabemos que nas sociedades atuais, e nas classes sociais, poucas mulheres se reconhecem no modelo da "dona de casa", incluindo, como vimos, entre as mais "zelosas". Resta, por enquanto, que os projetistas das organizações do trabalho masculino não integraram as evoluções das aspirações femininas.

\section{Conclusão}

As questões levantadas neste artigo provam que o campo aberto pela discussão entre a psicodinâmica do trabalho e a sociologia das relações sociais de sexo não é homogêneo do ponto de vista teórico, que é cruzado pelas tensões e controvérsias entre as duas disciplinas e entre os pesquisadores de cada disciplina. Além destas tensões, os conhecimentos construídos ao longo destes quinze anos levantam argumentos substanciais à tese segundo a qual a saúde não é um dom da natureza, mas uma construção intersubjetiva. Parece que nesta construção, o trabalho de cuidar realizado pelas mulheres, neste espaço produtivo como no espaço reprodutivo, tem um papel preponderante, hoje subestima-

As mulheres de homens que trabalham em turnos são "compreensivas". "Compreensiva, mesmo se isto me irrita", dirá uma delas. Constatamos, entre as mais velhas, um cansaço e uma irritação em relação à vida assim organizada e uma irritação contida frente a um marido que se guarda mais e mais e que se recupera durante o tempo de descanso. Um marido com quem precisa se preocupar mais e mais. Segundo as mulheres, seus esposos, em particular os jovens engenheiros, não são particularmente "machos". Eles não impõem a parada da atividade profissional a suas esposas. Eles se propõem a executar as tarefas domésticas, como vestir as crianças para levá-las à escola. "Mas eu prefiro fazer eu mesma", dirá a esposa, pois ele não combinará as meias com os elásticos das roupas! Para esta mulher super- qualificada, que provisoriamente renunciou ao trabalho, como para as mulheres não qualificadas pro- do. Também não se pode subestimar que este trabalho de cuidar de outros é freqüentemente questionado pelas organizações do trabalho que o desconhecem.

Fortalecida pelas contribuições da sociologia das relações sociais de sexo, a análise das situações do trabalho do pessoal de enfermagem permitiu mostrar que as modalidades da subjetividade, como a paciência, a receptividade, a sensibilidade à vulnerabilidade do outro, classicamente consideradas pela psicologia clínica como pertencentes à constelação psíquica da feminilidade e do "eu relacional" das mulheres, são, em sua maioria, diferenciações contingentes e secundárias à experiência do trabalho. Não considerando as teorias do trabalho, as teses convencionais da psicologia participam da ocultação do trabalho das mulheres, desfiguram sua experiência e acentuam o déficit crônico de reconhecimento que elas sofrem. A psicodinâmica do traba- 
lho, e mais particularmente meus próprios trabalhos se inscrevem numa perspectiva crítica frente à corrente anglo-saxônica da ética do cuidar (ethics of care). A compaixão não tem saída sem mediação da infantil feminina, ela não é a virtude natural das mulheres ou de certas dentre elas, mas o sofrimento gerado pelo trabalho de cuidar. A não motivação ou o esgotamento profissional (as duas vertentes do "burn out syndrom") não são fatalidades. Ao contrário. Quando seu destino patogênico é conjurado pelo coletivo enfermeiro, a compaixão, criadora de sentido, participa da realização de si. Quais lições podem-se tirar com relação à saúde das equipes que trabalham com cuidados aos outros, depende principalmente da qualidade das arbitragens sobre as contradições da organização do trabalho. O hospital chega a inventar compromissos organizacionais suficientes para salvar sua utilidade social e seu valor civilizador: além da cura dos corpos a um menor custo, a criação de um mundo comum onde o sofrimento não foi eliminado? Das respostas que serão dadas, depende nossa saúde.

A pesquisa realizada com as mulheres de homens que trabalham em turnos representa um desenvolvimento a mais na relação saúde-trabalho sob o ângulo combinado da psicodinâmica do trabalho e das relações sociais de sexo. Seu principal resultado é sem dúvida que ela foi realizada graças à vontade dos trabalhadores que trabalham em turnos. Por uma vez, os homens não se opuseram ao "trabalho doméstico da saúde" realizado por suas esposas ${ }^{9}$. Isto é um sinal de que alguma coisa na posição dos homens está mudando nas relações sociais de sexo? Gostaríamos de concluir sob um ângulo otimista. Infelizmente, se a virilidade parece se corroer, não há indicações de um progresso em matéria da saúde (a virilidade é uma defesa). A mesma pesquisa mostrou um intenso sentimento de vulnerabilidade do lado dos homens, através de "descompensação" pelas doenças graves ou por suicídios. Esta desagregação progressiva do universo do trabalho masculino é o que faria o fundamento da saúde de identidade masculina: autoridade, prestígio, conhecimento, orgulho do trabalho bem feito, solidariedade dos chefes com suas equipes. E se as mulheres fossem o último baluarte? A saúde daqueles que vivem próximos às fábricas? Qualquer que seja a evolução nestes casos precisos, vemos que as questões levantadas pela análise do trabalho das mulheres não são questões "específicas", elas concernem ao futuro do conjunto da sociedade.

\section{Tradução: Márcia Waks Rosenfeld Sznelwar}

\begin{abstract}
- Notas
${ }^{1}$ As enfermeiras compartilham os mesmos valores. Nos coletivos de enfermeiras, a virilidade não chega nunca ao mesmo status valorizado como nas atividades masculinas. Quando os enfermeiros da psiquiatria são constrangidos a utilizar a força física para controlar a violência dos doentes mentais, sua virilidade é "sem glória": utilizar a força ou a intimidação para controlar um paciente é explicitamente considerado como "um trabalho sujo" (MOLINIER, GUIJUZZA, 1997).

${ }^{2}$ Umas trinta participantes tinham entre 30 e 55 anos, a maioria com crianças.

${ }^{3}$ Eu me restrinjo às profissões da saúde aonde esta estratégia é favorecida pelo mercado de trabalho. Pelas mesmas razões, o ativismo está aqui relacionado com o sofrimento ético e não com o medo de perder o emprego, como é frequiente em outros casos.
\end{abstract}

${ }^{4}$ Para dar um exemplo, uma mulher, diretora de enfermagem, pediu sua saída depois de meses de conflito com o médico chefe do serviço. Ele recusava fechar as camas durante um período de reforma, pois estas possuíam problemas de segurança para os pacientes e mesmo para os trabalhadores. Cansada, exausta, ela, numa noite, voltando no carro sozinha do hospital, conduzia na estrada com os faróis apagados e na contra-mão.

${ }^{5}$ Salvo em certos serviços específicos (urgências, cuidados intensivos).

${ }^{6}$ As meninas teriam tendência a reconhecer a diferença anatômica dos sexos enquanto os meninos the oporiam uma negação. Eu deixo fora a discussão que, segundo Roiphe e Galenson, a negação acompanhará, para os meninos, reações agressivas enquanto reações depressivas serão associadas ao reconhecimento pelas meninas da diferença dos sexos. Segundo outros autores, estas mudanças de humor não serão sistemáticas e deverão ser interpretadas em função da relação mãe-filho e da relação dos pais para com sua própria identidade sexual (ver capítulo 16, in TYSON, TYSON, 1996.)

${ }^{7}$ As ideologias defensivas de profissão são estratégias coletivas de defesa radicalizadas. Elas correspondem a situações aonde as pessoas não podem construir mais compromissos satisfatórios com a organização do trabalho. A luta contra o sofrimento no trabalho corrói o sentido e mesmo a eficácia do trabalho.

\begin{abstract}
${ }^{8}$ Eu distingo aqui a identidade sexual da identidade nuclear do gênero que é o sentido de si mesmo feminino ou masculino (STOLLER 1968). A identidade nuclear do gênero se fixa durante o segundo ano de vida e representa "uma parte da identidade tão sólida que quase nenhuma das vicissitudes da vida a pode destruir" " (STOLLER, citado por TYSON et TYSON, pág. 333). A identidade sexual devolve a dimensão do corpo erótico ("fantasmatização" do corpo anatômico). A identidade sexual é instável, os bens trazidos e as modificações podem interferir ao longo da vida, e a deixar mais segura/garantida ou em crise.
\end{abstract}

${ }^{9}$ Para o conceito de "trabalho doméstico da saúde", cf. Cresson, 2000 


\section{- Bibliografia}

CRESSON, G. Les parents d'enfants hospitalisés à domicile. Leur participation aux soins. L'harmattan "Logiques sociales», 2000.

CHAPLAIN, D-L.,; CUSTOS-LUCIDI, MF. Les métiers de la petite enfance. Des professions en quête d'identité. Syros, 2001.

CHODOROW, N. The Reproduction of Mothering. Berkeley: University of California Press, 1978.

DEJOURS, C. Travail: usure mentale, Bayard, $3^{\text {ème }}$ ed. 2000, 1980.

DEJOURS, C. Souffrance en France, Seuil, 195 p., 1998.

DEJOURS, C. Adolescence : le masculin entre sexualité et société. Adolescence. 6 : 89-116, 1988

DEJOURS C. Centralité du travail et théorie de la sexualité, Adolescence, $14,2: 9-29,1996$

DEJOURS C. Différence anatomique et reconnaissance du réel dans le travail. Les Cahiers du Genre, 29: 101-126, 2000
DEJOURS, C. Les rapports domestiques: entre amour et domination. Travailler 8, 2002

CARPENTIER-ROY M-C.I. Corps et âme. Psychopathologie du travail infirmier. Montréal: Éditions Liber, 1991.

CASSELL, J. Différence par corps: les chirurgiennes. Les cahiers du Genre, 29: 53-82, 2000.

GILLIGIAN, C. Une si grande différence, Paris, Flammarion, 1982.

GRENIER-PEZÉ, M. Forclusion du féminin dans l'organisation du travail: un harcèlement de genre. Cahiers du Genre, 29 : 37-52, 2000.

HABIB, C. Le consentement amoureux. Hachette Littératures, 1998.

HIRATA, H.; KERGOAT D. Rapports sociaux de sexe et psychopathologie du travail. In Plaisir et souffrance dans le travail. Edition de I'AOCIP. Tome II, p. 131-176,1988.

HIRATA, H. Travail et affects. Les ressorts de la servitude domestique. Note de recherche. Travailler, $8: 13$ $26,2002$.
KERGOAT, D Le syllogisme de la constitution du sujet sexué féminin. Le cas des ouvrières spécialisées. Les rapports sociaux de sexe: problématiques, méthodologies, champs d'analyses, Iresco, 3 t. republié in Travailler. 2001, 6 : 105-114, 1988.

KERGOAT, D. Division sexuelle du travail et rapports sociaux de sexe, Dictionnaire critique du féminisme (Ed. Hirata, H; Laborie, F; Le Doaré, H Senotier, D), PUF: 35-44, 2000.

KERGOAT, D. Le rapports social de sexe. De la reproduction des rapports sociaux à leur subversion, Actuel Marx, 30: 85-100, 2001.

MOLINIER, P. Autonomie morale subjective et construction de l'identité sexuelle, Revue Internationale de psychosociologie, 5: 53-62, 1996.

MOLINIER, P.; GUIJUZZA, C. Violence des patients, souffrance et défenses des infirmiers en psychiatrie l'énigme d'une virilité sans gloire. Actes $d u 1^{\text {er }}$ colloque international de psychodynamique et psychopathologie du travail. (Ed Molinier, P.; Weber, H.) t. 2: 365-378, 1997
MOLINIER, P. Travail et compassion dans le monde hospitalier, Les cahiers du Genre, 28 : 49-70, 2000

MOLINIER, P. Souffrance et théorie de l'action, Travailler 7 : 131-146 ,2001

MOLINIER, P. Féminité sociale et construction de l'identité sexuelle perspectives théoriques et cliniques en psychodynamique du travail L'orientation scolaire et professionnelle, à paraître janvier 2003.

ROIPHE, H. GALENSON, E. Infantile Origins of Sexual Identity. New York. International University Press, Inc. Trad. franc. (1987) La naissance de l'identité sexuelle. Paris. PUF, 198

SCHELLER, L. Les bus ont-ils un sexe? Les femmes machinistes: approche psychodynamique de la division sexuelle à la RATP, Rapport de recherche, Département du Développement prospectives et recherches sociétales, RATP, n. 108, 1996.

STOLLER, R. Sexe and Gender. Trad. Française: Recherches sur l'identite sexuelle, 1978. Gallimard, 1968.

TYSON, P.; TYSON, R. L. Les théories psychanalytiques du développement de l'enfant et de l'adolescent, PUF, 1996. 